Article

\title{
Christian Accommodative Mindfulness: Definition, Current Research, and Group Protocol
} Fernando Garzon ${ }^{1, *}$, Andres Benitez-DeVilbiss ${ }^{1}$, Vera Turbessi ${ }^{1}$, Yaa Tiwaa Offei Darko ${ }^{1}$, Nelsie Berberena ${ }^{1}$,
Ashley Jens ${ }^{1}$, Kaitlin Wray ${ }^{1}$, Erica Bourne ${ }^{1}$, John Keay ${ }^{1}$, Jeffrey Jenks ${ }^{1}$, Courtney Noble ${ }^{1}$ and Carletta Artis ${ }^{2}$

Citation: Garzon, Fernando, Andres Benitez-DeVilbiss, Vera Turbessi, Yaa Tiwaa Offei Darko, Nelsie Berberena, Ashley Jens, Kaitlin Wray, Erica Bourne, John Keay, Jeffrey Jenks, and et al. 2022. Christian Accommodative Mindfulness: Definition, Current Research, and Group Protocol. Religions 13: 63. https://doi.org/ 10.3390/rel13010063

Academic Editor: Regina

Chow Trammel

Received: 2 December 2021

Accepted: 6 January 2022

Published: 11 January 2022

Publisher's Note: MDPI stays neutral with regard to jurisdictional claims in published maps and institutional affiliations.

Copyright: (C) 2022 by the authors. Licensee MDPI, Basel, Switzerland. This article is an open access article distributed under the terms and conditions of the Creative Commons Attribution (CC BY) license (https:// creativecommons.org/licenses/by/ $4.0 /$ )
1 Department of Graduate Psychology, Psy.D. Program, Regent University, Virginia Beach, VA 23464, USA; andrbe3@mail.regent.edu (A.B.-D.); veratur@mail.regent.edu (V.T.); yaaoffe@mail.regent.edu (Y.T.O.D.); nelsber@mail.regent.edu (N.B.); ashlje2@mail.regent.edu (A.J.); kaitwra@mail.regent.edu (K.W.); ericpa1@mail.regent.edu (E.B.); johnkea@mail.regent.edu (J.K.); jeffjen@mail.regent.edu (J.J.); cournob@mail.regent.edu (C.N.)

2 Department of Counseling Ministries, Regent University, Virginia Beach, VA 23464, USA; cartis@regent.edu

* Correspondence: fgarzon@regent.edu

\begin{abstract}
More clinicians are using mindfulness-based therapeutic strategies; however, Evangelical Christian clients sometimes worry about the Buddhist origins of these treatments. Christian accommodative mindfulness (CAM) attempts to address these concerns with culturally sensitive adaptations to mindfulness methods. We present a definition of CAM and propose some worldview adjustments to typical mindfulness constructs when working with these clients. The empirical research on Christian-derived meditation strategies and Christian-adapted mindfulness strategies will then be reviewed. We introduce a four-session group CAM protocol currently being researched that focuses on scripture meditation, breath meditation, body awareness, and loving-kindness meditation. Sample scripts are included.
\end{abstract}

Keywords: mindfulness; Christian research; health outcomes; behavioral health

\section{Introduction}

Scientific western psychology often studies various religious groups through an etic lens that examines religious experiences in a distant manner from the particular populations being investigated (Kim et al. 2000). Slowly, more emic, indigenous psychologies for religious populations are being developed (Sisemore and Knabb 2020). This approach holds promise for the Evangelical Christian population regarding mindfulness. Evangelical Christians derive from numerous Protestant denominations and represent a diverse group. They believe in salvation by grace through faith in Christ's atonement as a key doctrine (Noll 2003). They also emphasize a personal conversion experience and have a high regard for the bible as the word of God (Noll 2003).

In this article, we discuss Evangelicals' potential concerns with mindfulness and propose Christian accommodative mindfulness (CAM) as a potential resource to address these concerns. We define CAM and examine Evangelical worries that can impede mindfulness treatment. Accordingly, we introduce worldview elements that can be incorporated into mindfulness treatment to make it more adaptive to Evangelical concerns. The question of whether such adaptations lead to any empirical support for CAM naturally arises, so we then briefly review pertinent outcomes-based empirical research. Finally, we present our own four-session Christian accommodative mindfulness protocol as an example of what CAM treatment might look like. We hope this protocol will help non-Christian and Christian mental health professionals to provide culturally sensitive and more effective treatment when working with this population.

Evangelical Christian clients may have several concerns about mindfulness. Some worry about the Buddhist roots of mindfulness, as well as associations with the New Age 
movement (Garzon and Ford 2016). The religious fears can also lead certain individuals to wonder if they might be exposing themselves to possible demonic oppression. Therapists who do not recognize these potential reactions risk missing meaningful barriers to treatment that could result in iatrogenic injury. Consequently, CAM may be a part of culturally sensitive treatment. To begin describing aspects of CAM, we must first define it.

\section{Current Definitions of Christian Mindfulness}

Popular press articles and even most scholarly articles do not report a definition of CAM; however, some definitions have recently emerged. For example, Trammel and Trent (2021) propose mindfulness or variants of the construct interconnect with many religions. They share a Christian understanding of mindfulness, which includes activating one's awareness towards God's presence in this practice. Hence, "Christian mindfulness is about making time to turn our whole attention to God so that we can hear and abide in his voice above the chatter and stress of our lives." (p. 17).

We support the important principles highlighted in Trammel and Trent's definition and seek to expand on it in our view of Christian accommodative mindfulness (CAM). CAM maintains foundational historical Christian spiritual formation themes for the psychological and spiritual well-being of appropriately religious clients and applies two main forms of meditation: Christian-derived meditative strategies and adapted mindfulness meditations. Christian-derived strategies are methods seen in the history of Christianity (Johnson et al. 2013). These strategies include spiritual exercises that aim at increasing one's awareness of God (Frederick and White 2015). Adapted mindfulness strategies are mindfulness strategies seen in the empirical literature (from Eastern or secular sources) which are modified to align with a Christian worldview.

Some argue that no need exists to adapt Eastern or secular meditation in working with Christian clients since Christianity has its own rich history of meditation that can be used (Knabb 2021). We agree that Christianity does have sufficient resources for mindfulnesslike treatment with Christian clients, so we support the value of this emic approach. This support includes a caution, however. It is our observation that most Christian and certainly non-Christian mental health professionals have much more training in Eastern and secular mindfulness-based treatments (ACT, DBT, MBCT, MBSR, etc.) than they do Christian-derived methods. We believe it is much easier, especially for non-Christian therapists working with Christian clients, to transition from Eastern/secular mindfulness to adapted mindfulness than it is to learn Christian-derived methods which would be totally foreign for non-Christian therapists. Christian clinicians, of course, can learn both when exposed to either. For these reasons, CAM includes Christian-derived methods and supports their ongoing development, but it also incorporates adapted mindfulness strategies. Part of the adaptation includes adjusting certain mindfulness constructs.

\section{Applying a Christian Worldview to Mindfulness Constructs}

Several mindfulness constructs can be reframed to apply a Christian worldview more effectively for appropriately religious clients. Such adaptations may make mindfulness treatment more acceptable to Evangelical Christians. This nonexhaustive section will emphasize a few key adjustments that can make these treatment themes more spiritually congruent. Briefly, the roles of God's immanence and transcendence in present moment awareness will be described. Humble detachment and surrender will be contrasted with mindful detachment. An "outside-in" approach to developing self-compassion will be compared to mindfulness' more typical "inside-out" method. Potential pitfalls in nonjudgment will be addressed, and the importance of grace as a framework for acceptance of self and others will be described.

Unlike Buddhism, in Christianity, God is immanent and transcendent. This means that He is present, personal, and relational in the present moment as well as distinct from the created universe (Garzon and Ford 2016; Trammel and Trent 2021). This has direct implications for mindfulness strategies that seek to enhance present moment awareness. 
We become aware of our thoughts, feelings, and body sensations in the present moment while recognizing God's loving presence with us in the moment, too. Leaving God out means leaving half of reality out theologically for some Evangelicals. Incorporating an awareness of God's presence in addition to our body and mind-based self-experience can increase a client's satisfaction with treatment and reflects a key adaptation in CAM compared to secular or Eastern mindfulness methods. This feature will be reflected in each meditation of the protocol we share later in this article.

In addition to present moment awareness, secular or Buddhist mindfulness seeks to cultivate detachment from inner experiences to reduce suffering. Implicit with the emphasis on God's immanence noted above, Christianity includes God in this detaching process. In a survey study utilizing structural equation modeling, Knabb et al. (2018) identified humble detachment as a key Christian construct associated with decreased worry and rumination in participants. Humble detachment involves "a detached, flexible humble ability to (a) let go of the tendency to clutch or push away a preoccupation with inner experiences and the self, and (b) pivot from a preoccupation with the self and inner experiences to a more transcendent awareness of God's active, loving presence." (Knabb et al. 2018, p. 172). An individual's ability to yield uncomfortable internal experiences to God can help in the humble detachment process, ultimately disrupting those uncomfortable internal experiences from continuing to trigger and maintain anxiety and depression (Knabb et al. 2017, 2018). This yielding to God aspect is known as surrender, a beneficial religious coping style encompassing an active choice to turn over uncomfortable internal experiences or external situations outside of one's control to God (Wong-McDonald and Gorsuch 2000). Active surrender of the healing process to God multiplies the effectiveness of therapeutic work through enhanced meaning making (Trammel and Trent 2021).

In addition to detachment, mindfulness includes the cultivation of self-compassion which involves an individual's ability to self-soothe when they are suffering through lessening self-focus and self-criticism and increasing empathy for the self (Wilhoit 2018). Knabb (2019) notes that mindfulness practices normally utilize an "inside-out" approach to developing compassion. This inside-out perspective means that self-compassion emerges from an awareness of one's own suffering and the motivation to reduce one's pain. In contrast, Knabb observes that Christianity adopts an "outside-in" approach to develop self-compassion in which Christians draw upon God's active, loving presence while moving away from inner preoccupations related to self-interests and self-worry. Christians focus on their relationship with God and his mercy to alleviate suffering and detach from potentially destructive thoughts and feelings such as judgments (Knabb 2019; Symington and Symington 2012). By turning to their relationship with God, God's compassion is then received for the self and extended to others (Knabb 2019). Pointing Evangelicals towards God's loving mercy as a catalyst for self-compassion may be more effective than traditional inside-out mindfulness strategies. It may also lead to self-forgetfulness, which is a virtue understood as a middle position between self-preoccupation and mindless absorption where one can genuinely focus on the experience and needs of others (Wilhoit 2018). We apply an outside-in cultivation of self-compassion in our loving-kindness session shown later in this article.

Related to self-compassion, a key element of mindfulness involves cultivating nonjudgment. On the positive side, having a stance of nonjudgment and understanding helps one to grow in love towards family and friends, as well as communicate effectively with them (Trammel and Trent 2021). However, there are pitfalls. Some Christians might wonder whether adopting a completely nonjudgmental attitude would imply no moral code to evaluate thoughts and behaviors. Hoover (2018) proposes a useful approach to this dilemma. He notes that Christians appear to agree that they ought to be exceedingly cautious about making snap judgments (see Matthew 7:1; Matthew 26:52; Matthew 7:5). Such judgments are often uncalibrated and typically uncharacteristic of one's deepest values. Hoover proposes that mindfulness may be a vehicle to suspend this snap judgment process temporarily, permitting the practitioner to engage in discernment, a more metered, logical, 
reflective thinking style in assessing a situation. The Bible frequently emphasizes slowing down one's reactivity and recognizing transcendent reality (see Psalm 46:10). Temporary nonjudgment can be a safe position for Christians when framed within the long-term purpose of developing discernment (Hoover 2018).

Mindfulness strategies link nonjudgment with another important attitude-acceptance of self and others. Incorporating the foundational Christian construct, grace, can transform mindful acceptance strategies from the previously noted nonrelational inside-out process into a relational outside-in process. In traditional Christian theology, grace is defined as a gift of God, mediated through Jesus Christ, that is "bestowed freely and without regard to merit which manifests in the giving of blessings and granting of salvation" (Judd et al. 2020, p. 26). Judd and colleagues (2020) broaden this definition of grace to a "benevolent divine influence acting upon humanity to impart spiritual enrichment or purity, to inspire virtue, or to give strength to endure trial and resist temptation" (p. 26). While both definitions focus on God's relationship to humanity, grace can also occur between people. Emmons et al. (2017) capture both the spiritual and interpersonal aspects of grace with their description of it as "the gift of acceptance given unconditionally and voluntarily to an undeserving person by an unobligated giver [whether that be God or a person]. The gift is given without regard to the worthiness of the recipient" (p. 277).

In CAM, acceptance begins with clients' relationship with God as we "help our clients realize they cannot escape his grace, no matter what, because wherever they go, there God is" (Trammel and Trent 2021, p. 86). Gradually, clients expand their recognition of the incredible grace of God towards them, which can inspire both acceptance of self and others (Trammel and Trent 2021). Indeed, Hodge et al. (2020) meta-analysis suggests that strong belief in grace is associated with positive outcomes such as spiritual well-being, adaptive interpersonal functioning, and the cultivation of virtues such as humility and forgiveness. These findings demonstrate the potential value of including grace as a concept in treatment with appropriately religious clients. Grace can intersect with a variety of mindfulness themes beyond acceptance. Taken together with the other Christian constructs described above, applying a Christian worldview can provide a better foundation for mindfulness treatment for many Christians (Garzon and Ford 2016). This assertion warrants empirical examination.

\section{Empirical Research on CAM}

In contrast to the robust empirical support that exists for mindfulness-based secular therapies (Chua et al. 2021; Elices et al. 2017; Williams et al. 2008; Goldin and Gross 2010), CAM research is at an early stage of development. Nevertheless, examining this inchoate research will permit an initial evaluation of whether CAM may produce better outcomes with populations such as Evangelical Christians. Outcomes-based empirical studies can be divided into the two categories based on the type of meditation strategies that make up CAM (Christian-derived methods and adapted mindfulness methods).

\subsection{Christian-Derived Studies}

Research is growing on protocols that apply primarily Christian-derived methods (Montero-Marin et al. 2019). For example, the Jesus Prayer (the quiet repetition of "Lord, Jesus Christ, son of God, have mercy upon me, a sinner" or a shorter variant) has been studied in a quasi-experimental design and found to help participants from a community of middle-aged Catholics in Spain cope with burnout (Rubinart et al. 2017). Indeed, the Jesus Prayer and other Christian contemplative practices are intended to "rekindle one's spiritual connection to the divine." (Frederick et al. 2017, p. 273). Ferguson et al. (2010) examined the effects of centering prayer (repeating a sacred word that reflects one's consent to God's work and presence within, see Pennington 1986) with a small group of Catholic practitioners in a quasi-experimental design. The study suggested that participants experienced significant changes in their relationship with God as well as a reduction in stress as they practiced the centering prayer twice daily for 11 weeks. 
Some studies have combined several Christian-derived meditations in their protocol. Knabb et al. (2017) had participants practice various contemplative prayers in an 8-week pilot study for recurrent worry that led to promising results. A few randomized trials blending several Christian-derived methods have also occurred.

Knabb et al. (2020) investigated Christian-derived meditation's impact on repetitive negative thinking (rumination and worry) through a 4-week randomized wait-list control group study on two Christian university samples. The meditations utilized apophatic strategies (meditations that do not use imagery and minimal to no words) as well as kataphatic styles (meditations using both words and images). The researchers found large effects for the intervention group regarding an increase in nonattachment and a decrease in perseverative thinking. Medium effect sizes occurred in humility and surrender as a coping strategy as well.

In 2021, Knabb and colleagues examined trauma-based rumination in a community sample and a university sample. The online 4-week randomized wait-list control trial findings indicated the community sample experienced medium effect size decreases in trauma-based rumination and other trauma-related symptoms while the university sample experienced large effect sizes for increases in four mental skills (attention, present focus, awareness, and acceptance) as well as enhanced religious coping and communion with God.

\subsection{Adapted Mindfulness Studies}

Complementary to the above Christian-derived studies, research has evaluated the impact of adapting well-known mindfulness techniques with the Christian worldview. Some studies noted above for Christian-derived strategies incorporated adaptations to mindfulness meditations such as walking meditation as a part of their protocol (e.g., Knabb et al. 2021), and the studies in this section with primarily adapted strategies included scripture meditation (a Christian-derived strategy). Thus, the categories are not mutually exclusive but rather represent a continuum of emphasis.

Ford and Garzon (2017) conducted a randomized trial $(n=78)$ comparing CAM with conventional mindfulness training on university students. The protocol applied three types of adapted mindful meditation-breath, body awareness, and loving-kindness-over a three-week period. The results found significant differences between groups, with the CAM group showing lower levels of stress, depression, and total negative symptoms. The CAM group also demonstrated greater treatment adherence.

Only one study explored CAM with a clinical population. Jones et al. (2021) conducted an N-of-1 time-series study investigating CAM's impact on shame, depression, anxiety, and spiritually based resiliency factors. Five Christian outpatient clients suffering depression or anxiety-related disorders participated. The six-week protocol contained breath, body awareness, loving-kindness, scripture meditation, the Jesus Prayer, and a shame-related meditation. For every participant, CAM treatment was associated with medium to strong effect sizes on a minimum of five out of the nine outcome measures used and three subjects showed medium to strong effect sizes on eight of nine measures.

Trammel (2018) combined apophatic, kataphatic, and adapted mindfulness strategies in a randomized waiting-list controlled study investigating the effects of audio meditation on state mindfulness and perceived stress in a Christian university student population. Eighty participants completed the study and the audios for the treatment group were emailed over a six-week period. The treatment group displayed increased mindfulness and decreased stress (medium effect sizes) compared to the control group.

Trammel et al. (2021) also conducted a pilot study on 22 social workers utilizing a similar emailed audio meditation strategy found in her 2018 study. The findings suggested medium to large effects for increasing mindfulness and heart rate variability (HRV), as well as a small effect for reducing personal burnout in social workers. 


\subsection{Summary of the Current CAM Outcomes-Based Literature}

CAM literature is gradually growing. Present results from randomized trials on university and community samples are encouraging for both in-person and online CAM treatment for normal populations. While no study sought to just study Evangelical Christians, it is likely many were involved in the university and community samples. One clinical case study experiment also suggests the potential of CAM with clinical populations. These promising results can be improved with randomized studies that include longitudinal outcomes data (3-6 months post-treatment, for example) and more studies with clinical populations. Attrition has been a difficulty in some online studies (Knabb et al. 2021), so ongoing methodological refinement for these strategies is also recommended. The findings support the merits of continued research on CAM protocols. A sample protocol will now be offered. We recognize, of course, that a client's individual theological beliefs may lead to different prayer forms being more appropriate. An in-depth analysis of this important consideration is beyond the scope of this article. Furthermore, we acknowledge that there are inherent limitations in just focusing on the therapeutic aspects of prayer when it is used for so many spiritually based reasons. Nevertheless, we hope the protocol provided will prove useful for many Evangelical Christian clients.

\section{Group Protocol with Example Scripts}

Table 1 displays the goals and outlines for each module of the current four-week CAM protocol. It should be noted that this is not a comprehensive CAM protocol but reflects an initial set of modules to provide a brief introduction to CAM. Randomized trials and clinical time series studies have included three of the modules (scripture, breath, and body awareness), lending empirical support to them, while the fourth module (self-compassion) is yet to be researched outside of pilot studies (Ford and Garzon 2017; Jones et al. 2021; Knabb et al. 2020, 2021). Each week follows a roughly similar outline: didactics and group discussion, collecting subjective units of distress scale ratings (SUDS) pre-practice, meditation practice, collecting post-practice SUDS ratings, debriefing, and introducing at-home practice for the week.

The protocol was administered in a Zoom-based HIPPA compliant format due to COVID-19. Current evidence suggests that such telepsychology-based treatment is equally effective compared to in-person treatment for a variety of disorders (Turgoose et al. 2018; Varker et al. 2019). The protocol may be obtained through emailing the researchers. We comment below on particular facets of each session that may be useful for therapists applying the protocol in individual or group treatment formats. Week One introduces an adaptation of a stress model focusing on the role of rumination and worry in producing stress and anxiety (González et al. 2017; Tang et al. 2015). See Figures 1 and 2 for this model exemplifying struggles with stress related to rumination and worry and how various CAM meditations may lead to enhanced emotion regulation, increased ability to walk in the fruit of the Spirit (Galatians 5:22-23), and other positive psychospiritual outcomes.

After this introduction, group leaders share biblical support for the value of Christian meditation in coping and introduce scripture meditation as the first practice for the group to try in the coming week. See Garzon (2013) for a version of this meditation script. CAM begins with scripture meditation in group format because it serves as the safest way to ease participants into CAM. This would be especially important to consider with participants who express skepticism or reservations about the use of meditation, given that there is ample biblical support for meditating on scripture, God's character, and God's works in creation. After practicing the meditation, group members reflect on their experiences and discuss optimal times for them to practice the meditation for $10 \mathrm{~min}$ daily. 
Table 1. Four-week Christian accommodative mindfulness (CAM) group protocol outline.

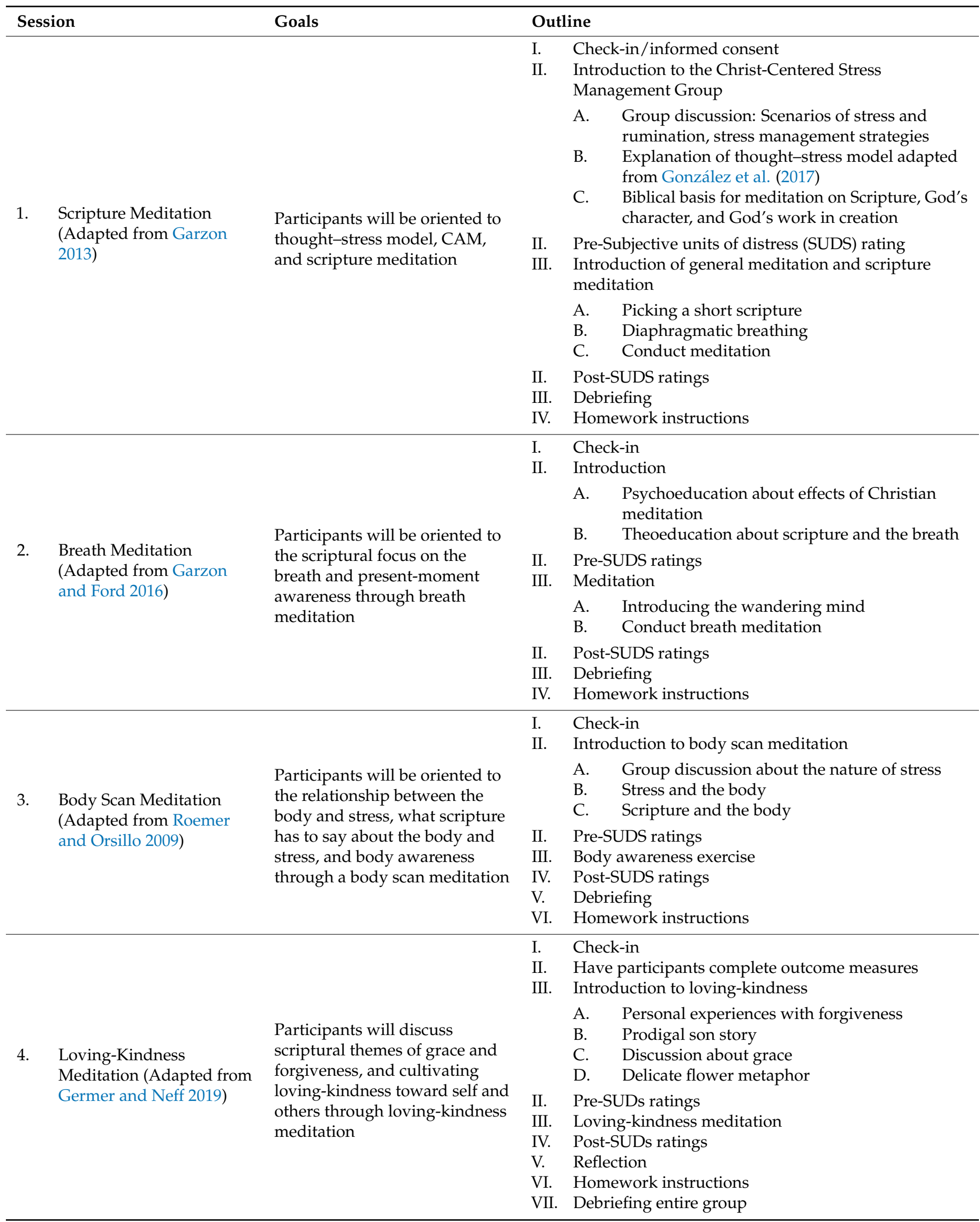




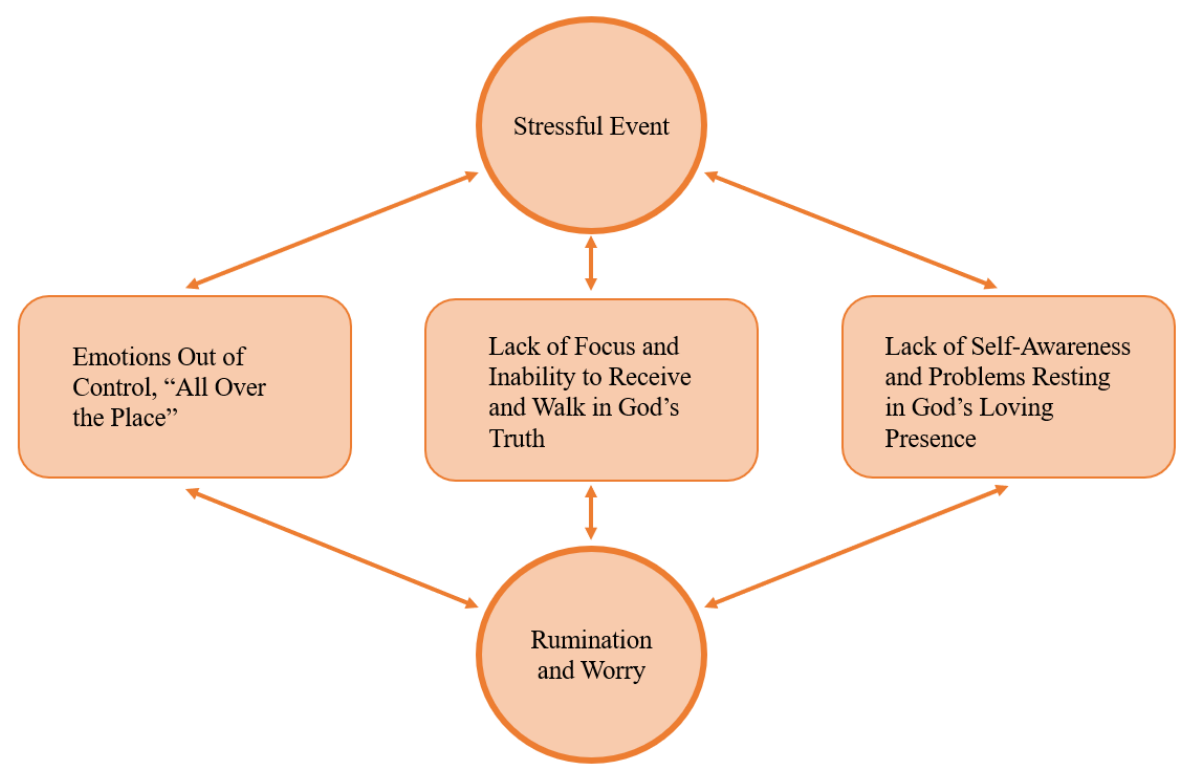

Figure 1. Roles of rumination and worry (adapted from Tang et al. 2015).

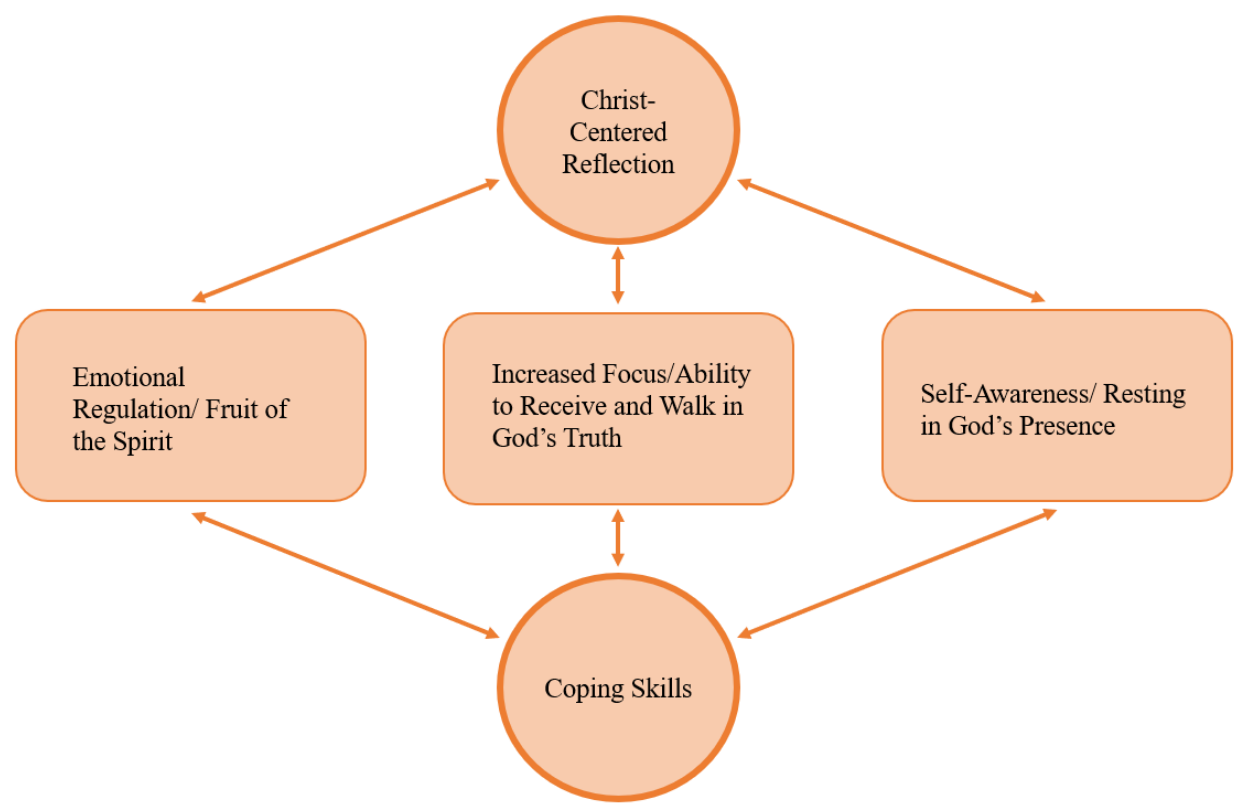

Figure 2. Benefits of Christ-centered reflection.

The next two weeks introduce breath meditation and body scan meditation (respectively), which focus on linking these concepts to scripture to facilitate comfort with bodily experiences and present moment awareness. Depending on the perceived needs of the participants, body scan meditation and breath meditation can be rotated as they address similar processes. Additionally, if using the protocol in individual therapy and the client does not express any level of concern toward meditation concepts, the second and/or third modules may be introduced first when clinically appropriate. For example, some trauma clients dissociated from their bodies may benefit from starting with breath or body-related methods in individual therapy. A script of the breath meditation adapted for this research can be found in Garzon and Ford (2016). Below a script for the body awareness protocol is presented, adapted from Roemer and Orsillo (2009) and Garzon (2015).

I'd like you to sit comfortably with your feet on the floor and your eyes closed or find a comfortable spot in the room to focus on. Notice the sounds in the room. What three sounds do you hear? ... Begin to turn your awareness to your body. 
Feel how you're sitting in the chair...how your hips feel on the chair. Notice how your hands are positioned and how they feel ... Observe how your back feels...If your mind wanders, that's okay. That's just what minds do. Just bring yourself back to the meditation. Observe how your clothes feel on your shoulders ... Notice how your face feels ... See if you can sense any differences in temperature with how the air feels around your face, perhaps some places are cooler than others ... Feel your feet in your shoes pressing against the floor ... Notice your clothes against your legs ... Just be aware of your experience, what is happening right now in this moment ... while you're observing this experience, I invite you to become aware of God's presence with you today, that He's here with you and wants to care for you in your experience.

I invite you to yield all you are experiencing to the Lord in this moment....Let go in His presence, releasing your tensions, thoughts, and worries into His hands. Jesus says "Come unto me, all of you who are weak and heavy laden, and I will give you rest." Just be with God ... As we close this activity, perhaps you would like to close with a quiet prayer. And when you're ready, open your eyes.

The protocol ends with loving-kindness meditation. Participants typically found this week to be simultaneously the most challenging and rewarding. Loving-kindness meditation involves internalizing an embodied attitude of compassion toward the self and others and requires a level of acquired skill in CAM practice. Accordingly, this module was placed at the end of the protocol so that the first three weeks could help cultivate attitudinal changes that might be useful in loving-kindness meditation. Further explanation of this session follows as a variety of Christian principles are useful in helping Evangelical clients cultivate this attitude.

Participants reflect on what it feels like when someone has forgiven them for something. This creates a personal anchor for experiencing loving-kindness. A biblical story, the prodigal son, (Luke 15:11-32) then highlights God's loving response to us when we have sinned and return to Him. Some verses and teaching on grace help reinforce God's unconditional love and acceptance of us even when we have a difficult time accepting ourselves. Finally, an analogy using a photo of two hands holding a bunch of delicate flowers highlights how we are called to hold our inner experience gently and kindly, like God holds us through grace, to keep from crushing the tender parts of our fragile experience. As might be anticipated, in our research, some participants expressed frustration at a perceived inability to do the meditation well while others verbalized benefiting greatly from the practice. A few reported they experienced the onset of difficult memories. When this occurred, the group leaders ensured the participants were stable and grounded and another meditation that was not triggering was suggested for the weekly practice. This highlights the importance of adapting CAM practices to fit the individual client experience either in group or individual therapy. After debriefing about the meditation, group leaders discussed with participants the group more generally before concluding the program. Below a script for the self-compassion meditation is presented, adapted from Germer and Neff (2019).

This exercise is designed to help you connect with God in a way that invites warmth and goodwill into your life. Sit in a comfortable position, close your eyes or find a spot to rest your eyes comfortably in the room. Allow your mind and body to settle with a few deep breaths. Put your hands over your heart to remind yourself that you are bringing not only attention, but loving attention, to your experience. If this position is uncomfortable for you, you may choose to place your hands in your lap or by your side, whichever is more restful for you. For a few minutes, feel the warmth of your hands and their gentle pressure over your heart. Allow yourself to be soothed by the rhythmic movement of your breath beneath your hands ... Now bring to mind a person who naturally makes you smile. This could be a friend, a close family member, whoever brings happiness 
to your heart. Feel what it's like to be in that person's presence. Allow yourself to enjoy the good company.

Next, recognize how vulnerable this loved one is-just like you, subject to many difficulties in life. Also, this person wishes to be happy and free from suffering, just like you and every other person. Repeat these prayers softly and gently to God, allowing the significance of your words to resonate in your heart... May this person be safe in Your love ... May Your Spirit guide them ... May You grant them peace ... May Your Spirit renew them ... May this person [substitute name if in individual therapy] find shelter in Your presence. Should you notice that your mind has wandered, return to the image of your loved one. Savor any warm feelings that may arise. Go slowly. Repeat these prayers again to God, allowing the words to resonate within ... May this person be safe in Your love ... May Your Spirit guide them ... May You grant them peace. May Your Spirit renew them ... May this person find shelter in Your presence. If you notice any discomfort, let it linger in the background and return to the phrases, or refocus on your loved one or your breath ... Now visualize your own body in your mind's eye, noticing any sensations, just as they are. Notice any discomfort or uneasiness that may be there.

Let's continue these prayers to God but this time, the prayers will be about yourself. Listen to the following prayers and repeat them after you hear them read-if one resonates more for you, use that one. What do you need to hear right now?... May I be safe in Your love ... May Your Spirit guide me ... May You grant me peace ... May Your Spirit renew me ... May I find shelter in your presence. It is normal to feel a slight uneasiness or discomfort when using lovingkindness toward yourself. If these feelings come up for you, simply notice them and return your attention to the present moment as we repeat these prayers again ... May I be safe in Your love ... May Your Spirit guide me ... May You grant me peace ... May Your Spirit renew me ... May I find shelter in your presence. If you notice any discomfort, let it linger in the background and return to the prayers, or refocus on your loved one or your breath. Remember to continue breathing deeply. Again, visualize your own body in your mind's eye and feel any sensations that may arise. If any discomfort or uneasiness is there, just notice it without judgment.

As we come to the end of the meditation, take a moment to reflect on this feeling of loving-kindness for yourself and your loved ones ... . . . (pause) In a moment, the meditation will end. We hope that you leave this meditation with a sense of accomplishment and peace for practicing this act of compassion. Whenever you are ready, gently open your eyes and return your attention to the room.

\section{Conclusions}

CAM holds promise as a resource for non-Christian and Christian mental health professionals working with Evangelicals who may have concerns with standard mindfulnessbased treatment modalities. A small empirical literature is demonstrating support for its efficacy, and more research is needed. As always, a spiritual assessment would be essential to avoid stereotyping and confirm the utility of CAM with any Christian client. When appropriate, mindfulness meditations can be adapted to the Christian worldview, and meditations derived from the Christian tradition can also be applied. The protocol presented here is an example of adapting mindfulness meditations to the Christian worldview that is suitable for non-Christian mental health professionals trained in mindfulness-based therapies and Christian mental health professionals more familiar with such methods. Examples featuring Christian-derived methods are also available in the literature (Knabb 2019, 2021; Knabb and Frederick 2017; Trammel and Trent 2021). 


\begin{abstract}
Author Contributions: Development of the protocol presented in Section 5, All authors except C.A.; All paper sections and editing, F.G.; Protocol, references, and editing, A.B.-D.; Section 1 draft: V.T.; Section 2 draft, Y.T.O.D. and N.B.; Section 3 draft, A.J., K.W. and E.B.; Section 4 draft, J.K. and J.J.; Section 5 draft, A.B.-D., C.N., F.G. and C.A.; Section 6, F.G. All authors have read and agreed to the published version of the manuscript.
\end{abstract}

Funding: This research received no external funding.

Institutional Review Board Statement: Not applicable.

Informed Consent Statement: Not applicable.

Data Availability Statement: Not applicable.

Conflicts of Interest: The authors declare no conflict of interest.

\title{
References
}

Chua, Joelle, Yan Xin, and Shefaly Shorey. 2021. The Effect of Mindfulness-Based and Acceptance Commitment Therapy-Based Interventions to Improve the Mental Well-Being Among Parents of Children with Developmental Disabilities: A Systematic Review and Meta-Analysis. Journal of Autism and Developmental Disorders, 1-14. [CrossRef]

Elices, Matilde, Joaquim Soler, Albert Feliu-Soler, Cristina Carmona, Thais Tiana, Juan C. Pascual, Azucena García-Palacios, and Enric Álvarez. 2017. Combining Emotion Regulation and Mindfulness Skills for Preventing Depression Relapse: A RandomizedControlled Study. Borderline Personality Disorder and Emotion Dysregulation 4: 13. [CrossRef]

Emmons, Robert A., Peter C. Hill, Justin L. Barrett, and Kelly M. Kapic. 2017. Psychological and Theological Reflections on Grace and its Relevance for Science and Practice. Psychology of Religion and Spirituality 9: 276-84. [CrossRef]

Ferguson, Jane K., Eleanor W. Willemsen, and MayLynn V. Castañeto. 2010. Centering Prayer as a Healing Response to Everyday Stress: A Psychological and Spiritual Process. Pastoral Psychology 59: 305-29. [CrossRef]

Ford, Kristy, and Fernando Garzon. 2017. Research Note: A Randomized Investigation of Evangelical Christian Accommodative Mindfulness. Spirituality in Clinical Practice 4: 92-99. [CrossRef]

Frederick, Thomas, and Kristen M. White. 2015. Mindfulness, Christian Devotion Meditation, Surrender, and Worry. Mental Health, Religion \& Culture 18: 850-58.

Frederick, Thomas V., Scott Dunbar, and Yvonne Thai. 2017. Burnout in Christian Perspective. Pastoral Psychology 67: 267-76. [CrossRef]

Garzon, Fernando. 2013. Christian devotional meditation for anxiety. In Evidence-Based Practices for Christian Counseling and Psychotherapy. Edited by Jamie Aten, Eric Johnson, Everett Worthington and Joshua Hook. Downers Grove: Intervarsity Academic Press, pp. 59-76.

Garzon, Fernando. 2015. Mindfulness or Christian Present Moment Awareness? Different Options with Different Results. AACC Newsletter: Christian Counseling Connection 20: 7.

Garzon, Fernando, and Kristy Ford. 2016. Adapting Mindfulness for Conservative Christians. Journal of Psychology and Christianity 35: 254-59.

Germer, Christopher, and Kristin Neff. 2019. Teaching the Mindful Self-Compassion Program. New York: Guilford Press.

Goldin, Philippe R., and James J. Gross. 2010. Effects of Mindfulness-Based Stress Reduction (MBSR) on Emotion Regulation in Social Anxiety Disorder. Emotion 10: 83-91. [CrossRef]

González, Manuel, Ignacio Ibáñez, and Andrea Barrera. 2017. Rumination, Worry and Negative Problem Orientation: Transdiagnostic Processes of Anxiety, Eating Behavior and Mood Disorders. Acta Colombiana de Psicología 20: 42-52.

Hodge, Adam S., Joshua N. Hook, Don E. Davis, Daryl R. Van Tongeren, Rodger K. Bufford, Rodney L. Bassett, and Mark R. McMinn. 2020. Experiencing Grace: A Review of the Empirical Literature. The Journal of Positive Psychology, 1-14. [CrossRef]

Hoover, Jonathan. 2018. Can Christians Practice Mindfulness Without Compromising Their Convictions? Journal of Psychology and Christianity 37: 247-55.

Johnson, Eric L., Everett L. Worthington, Joshua N. Hook, and Jamie D. Aten. 2013. Evidence-Based Practice in Light of the Christian Tradition(s): Reflections and Future Directions. In Evidence-Based Practices for Christian Counseling and Psychotherapy. Edited by Everett L. Worthington, Eric L. Johnson, Joshua N. Hook and Jamie D. Aten. Downers Grove: InterVarsity Press.

Jones, Tracy L., Fernando L. Garzon, and Kristy M. Ford. 2021. Christian Accommodative Mindfulness in the Clinical Treatment of Shame, Depression, and Anxiety: Results of an N-of-1 Time-Series Study. Spirituality in Clinical Practice, 1-13. [CrossRef]

Judd, Daniel K., Justin W. Dyer, and Justin B. Top. 2020. Grace, Legalism, and Mental Health: Examining Direct and Mediating Relationships. Psychology of Religion and Spirituality 12: 26-35. [CrossRef]

Kim, Uichol, Young-Shin Park, and Donghyun Park. 2000. The Challenge of Cross-Cultural Psychology: The Role of Indigenous Psychologies. Journal of Cross-Cultural Psychology 31: 63-75. [CrossRef]

Knabb, Joshua J. 2019. The Compassion-Based Workbook for Christian Clients: Finding Freedom from Shame and Negative Self-Judgments. New York: Routledge.

Knabb, Joshua J. 2021. Christian Meditation in Clinical Practice: A Four-Step Model and Workbook for Therapists and Clients. Downers Grove: Intervarsity Press. 
Knabb, Joshua J., and Thomas V. Frederick. 2017. Contemplative Prayer for Christians with Chronic Worry: An Eight-Week Program. New York: Routledge.

Knabb, Joshua J., Thomas V. Frederick, and George Cumming. 2017. Surrendering to God's Providence: A Three-Part Study on Providence-Focused Therapy for Recurrent Worry (PFT-RW). Psychology of Religion and Spirituality 9: 180-96. [CrossRef]

Knabb, Joshua J., Veola E. Vazquez, Fernando L. Garzon, Kristy M. Ford, Kenneth T. Wang, Kevin W. Conner, Steve E. Warren, and Donna M. Weston. 2020. Christian Meditation for Repetitive Negative Thinking: A Multisite Randomized Trial Examining the Effects of a 4-Week Preventative Program. Spirituality in Clinical Practice 7: 34-50. [CrossRef]

Knabb, Joshua J., Veola E. Vazquez, Kenneth T. Wang, and M. Todd Bates. 2018. “Unknowing” in the 21st Century: Humble Detachment for Christians with Repetitive Negative Thinking. Spirituality in Clinical Practice 5: 170-87. [CrossRef]

Knabb, Joshua J., Veola E. Vazquez, Robert A. Pate, Fernando L. Garzon, Kenneth T. Wang, DeAndra Edison-Riley, Alexandra R. Slick, Royalle R. Smith, and Sarah E. Weber. 2021. Christian Meditation for Trauma-Based Rumination: A Two-Part Study Examining the Effects of an Internet-Based 4-Week Program. Spirituality in Clinical Practice, 1-19. [CrossRef]

Montero-Marin, Jesus, Maria C. Perez-Yus, Ausias Cebolla, Joaquim Soler, Marcelo Demarzo, and Javier Garcia-Campayo. 2019. Religiosity and Meditation Practice: Exploring Their Explanatory Power on Psychological Adjustment. Frontiers in Psychology 10: 630. [CrossRef]

Noll, Mark. 2003. The Rise of Evangelicalism: The Age of Edwards, Whitfield, and the Wesleys. Downers Grove: Intervarsity Press.

Pennington, M. Basil. 1986. Centered Living: The Way of Centering Prayer. Garden: Doubleday.

Roemer, L. O., and S. M. Orsillo. 2009. Mindfulness and Acceptance-Based Behavioral Therapies in Practice. New York: Guilford Press.

Rubinart, Marta, Albert Fornieles, and Joan Deus. 2017. The Psychological Impact of the Jesus Prayer among Non-Conventional Catholics. Pastoral Psychology 66: 487-504. [CrossRef]

Sisemore, Timothy A., and Joshua J. Knabb. 2020. The Psychology of World Religions and Spiritualities: An Indigenous Perspective. West Conshohocken: Templeton Press.

Symington, Scott H., and Melissa F. Symington. 2012. A Christian Model of Mindfulness: Using Mindfulness Principles to Support Psychological Well-Being, Value-Based Behavior, and the Christian Spiritual Journey. Journal of Psychology and Christianity 31: 71-77.

Tang, Yi-Yuan, Britta K. Holzel, and Michael I. Posner. 2015. The Neuroscience of Mindfulness Meditation. Nature Reviews Neuroscience 16: 213-25. [CrossRef] [PubMed]

Trammel, Regina. 2018. Effectiveness of an MP3 Christian Mindfulness Intervention on Mindfulness and Perceived Stress. Mental Health, Religion \& Culture 21: 500-14.

Trammel, Regina, and John Trent. 2021. A Counselor's Guide to Christian Mindfulness: Engaging the Mind, Body, and Soul in Biblical Practices and Therapies. Grand Rapids: Zondervan.

Trammel, Regina, Gewnhi Park, and Ian Karlsson. 2021. Religiously Oriented Mindfulness for Social Workers: Effects on Mindfulness, Heart Rate Variability, and Personal Burnout. Journal of Religion \& Spirituality in Social Work: Social Thought 40: 19-38.

Turgoose, David, Rachel Ashwick, and Dominic Murphy. 2018. Systematic Review of Lessons Learned from Delivering Tele-Therapy to Veterans with Post-Traumatic Stress Disorder. Journal of Telemedicine and Telecare 24: 575-85. [CrossRef]

Varker, Tracey, Rachel M. Brand, Janine Ward, Sonia Terhaag, and Andrea Phelps. 2019. Efficacy of Synchronous Telepsychology Interventions for People with Anxiety, Depression, Posttraumatic Stress Disorder, and Adjustment Disorder: A Rapid Evidence Assessment. Psychological Services 16: 621-35. [CrossRef]

Wilhoit, James C. 2018. Self-Compassion as a Christian Spiritual Practice. Journal of Spiritual Formation and Soul Care 12: 71-88. [CrossRef]

Williams, J. Mark G., Ian Russel, and Daphne Russell. 2008. Mindfulness-Based Cognitive Therapy: Further Issues in Current Evidence and Future Research. Journal of Consulting and Clinical Psychology 76: 524-29. [CrossRef]

Wong-McDonald, Ana, and Richard L. Gorsuch. 2000. Surrender to God: An Additional Coping style? Journal of Psychology and Theology 28: 149-61. [CrossRef] 